\title{
28 Research Square \\ Challenges of Providing Health Services to Cardiovascular Patients in Emergencies and Disasters in Iran: A Qualitative Study
}

\section{Shandiz Moslehi}

Iran University of Medical Sciences

Fahimeh Barghi Shirazi ( $\square$ fshirazi63@gmail.com )

Iran University of Medical Sciences

\section{Research Article}

Keywords: Challenges, Health Services, Cardiovascular Diseases, Emergencies and Disasters

Posted Date: October 26th, 2021

DOl: https://doi.org/10.21203/rs.3.rs-966311/v1

License: (c) (1) This work is licensed under a Creative Commons Attribution 4.0 International License.

Read Full License 


\section{Abstract}

Introduction: Cardiovascular diseases are the most common cause of death in the world. Due to the rate of emergencies and disasters in the country, This study was conducted to investigate the challenges of providing health services to cardiovascular patients in emergencies and disasters in Iran.

Methods: This conventional content analysis study was conducted in 2020. Subjects were selected from among Iranian experts using purposeful and snowball sampling methods. Data were collected using semi-structured interviews and were analyzed by the content analysis.

Results:. After analyzing the data, in the Pre-emergency Phase (lack of training on medication and nutrition, and lack of training vulnerable groups, lack of databases of cardiovascular patients, and lack of identification of patients before disasters), The Emergency Response Phase (lack of sleep and rest patterns, lack of health forces, lack of blood pressure control, lack of proper nutrition, increased medication needs, lack of mental health interventions) and the Post-emergency phase (lack of planning, lack of management of patients' mental problems).

Conclusion: Developing strategies for planning, training, providing resources, and mental health during the 3 phases of emergencies management cycle for specific groups such as cardiovascular patients together with empowering these patients in the event of disasters is one of the key strategies which can be used after curbed emergences' and disasters to reduce the rate of mortality.

\section{Introduction}

Emergencies and disasters are harmful events which can occur of human origins (due to errors or an intent to destroy an individual, a group or a country) or because of natural disaster (based on the periodic pattern of nature) and disrupt the natural process of human life. Disasters and Emergencies are as old as the history of human life, and even today no society can be considered immune from them.

Complications as well as human and financial injuries caused by natural and unnatural emergencies and disasters have a very significant and undeniable impact on human life and health to the extent that they seriously disrupt societies in relation to the provision of vital needs (1). The International Federation of Red Crescent and the Red Cross Societies reported in 2002, emergencies and disasters affected the lives of approximately 170 million people worldwide (2). In the last decade, nearly 2 billion people in the world, about one-sixth of the world's population, have been directly and indirectly involved in disasters (3).

Providing health services is one of the most vital pillars of disaster management. As a result, effective evidence-based arrangements need to be made to provide health services in the event of an emergencies. Health care has its own characteristics and complexities which distinguish it from other organizations and social roles involved in crises. Health care is provided in many various types and in different organizations with different levels of management complexity, all of which require human resources with different specialties and teamwork (4). 
Although health care systems themselves are one of the most important organizations involved in disaster management, disasters and emergencies can seriously affect these health care delivery systems (by destroying health care facilities or reducing manpower). For example, in the Algerian earthquake, 50\% of hospitals and health centers and in Iran, in the Bam earthquake, all hospitals and health centers were destroyed (5). This highlights the importance of preparing and organizing health care systems in the face of disasters.

The response to providing health services in times of disasters and emergencies, is generally focused on the management of acute conditions and diseases such as traumatic injuries or infectious diseases (6). However, one of the most important challenges in providing health care during disasters and crises is related to neglecting chronic and non-communicable diseases. In such circumstances, the important and essential needs of people with chronic and non-communicable diseases are ignored (7)while people with chronic diseases are among the most vulnerable groups in disasters and emergencies.

It is clear that in the today's world, especially in developing and underdeveloped countries, noncommunicable diseases such as diabetes, cancer, cardiovascular diseases and chronic respiratory diseases are the most important causes of disability and mortality (7). Non-communicable disease management requires continuous provision of efficient and effective health care (8). Providing this integrated and ongoing care in emergencies situations and disasters will face major challenges. These challenges can be classified into two dimensions, including the health status of people with chronic diseases and the health care delivery system. First, accidents and disasters can directly worsen the condition of patients with chronic diseases by exacerbating stress, and on the other hand, they can indirectly lead to intensification of complications and injuries caused by diseases, through breaking the chain of providing quality and effective services (9). In such cases, poor control of chronic diseases may act as a serious threat to the health of people with these diseases. As a result, a comprehensive approach to managing chronic diseases and providing related health services in critical situations and disasters is needed. The importance of this issue in the operational plan of the World Health Organization for the prevention and control of non-communicable diseases during the years 2013-2020 was also seriously considered (10). The World Health Organization guidelines emphasize that continuous access to health care related to non-communicable diseases must be ensured during and after emergencies and disasters (10).

Among chronic diseases, cardiovascular ones are of particular importance. Cardiovascular diseases are the leading cause of death and disability worldwide. More than $12 \%$ of the global disease burden is related to cardiovascular diseases (11). It is estimated that by 2030 , more than 23 million deaths will occur annually due to cardiovascular diseases worldwide (12). In Iran where $58 \%$ of life years are with disability (DALY) related to chronic diseases, cardiovascular diseases are the deadliest cause of mortality (13). $50 \%$ of all deaths in the country and $79 \%$ of deaths related to chronic diseases are due to cardiovascular ones (13). In Iran, as in other less developed countries, cardiovascular diseases affect people of different age groups (13). The burden of cardiovascular diseases in the country is very significant and this situation becomes more complicated over time. For example, the results of forecasts 
indicate that the number of life years with disability attributed to cardiovascular diseases, which, in 2005, was close to 850 thousand years, in 2025, will arrive to more than 1.7 million years (13).

Iran is one of the most emergencies -prone countries in the world, where the level of disaster risk is calculated 8 out of 10 . Out of 42 known types of disasters, at least 31 types have occurred in Iran (14). For example, given Iran's location in the Alpine-Himalayan earthquake belt, it is one of the top ten earthquake-prone countries in the world, and many of its people have been victims of such events (14). Over the past four decades, natural disasters have killed nearly 110,000 people in Iran and have affected 53 million people (15). Between 2000 and 2018, there were 210 disasters and crises which caused more than 33,000 deaths and affected more than three million people (16). Unnatural disasters in Iran, including 8 years of the Holy Defense, road accidents and fires occurred in recent decades, have also taken many victims and have caused major damages to the socio-economic system of the country.

Despite these facts that Iran is an emergencies -prone country, the results of studies indicate that the provision of health care in disasters and accidents in the country is undesirable (5). In this regard, and for effective management of health care delivery in the event of emergencies and disasters, first, it is necessary to identify potential challenges related to the provision of health services in the event of disasters. Adequate studies have not been conducted in the field of health services, and few studies in this regard have only examined the general state of the health service system $(5,15)$, so that the challenges of providing health services to special and vulnerable groups of patients, such as ones with cardiovascular disorders, who involve a significant percentage of the country's population, have not been addressed. Therefore, this study aimed to identify the challenges of providing health services in the event of disasters and emergencies in Iran and from the perspective of experts. The results of this study can provide appropriate scientific and practical evidence to relevant policy makers and planners for future planning and preparing the country against disasters.

\section{Methods}

"The study was approved by the iran University of Medical Sciences and was conducted in accordance with the principles of the Declaration of Helsinki" Descriptive qualitative research design was used $\square$ Since the aim of this study was to provide health services to cardiovascular patients in the event of emergencies and disasters, the information was extracted by content analysis.

\section{Ethical Considerations}

This study has been approved by the institutional review board of the School of the Health Economics Research Center of the Management and Information Iran University of Medical Sciences(IR.IUMS.REC.1399.513). Participants were informed that participation in the study is voluntary and they could withdraw from the study at any time. Informed consent was obtained from all the participants. The IRB also confirmed that all methods were performed in accordance with relevant guidelines and regulations. 


\section{Participants}

The participants of this study were 16 experts in the field of disaster health and service delivery (physicians, nurses, health experts and from other related fields), 3 managers in the field of disaster health, 3 nursing managers with key positions in policy making for nursing, 3 managers in the field of health, 2 cardiologists, 3 masters of health, 1 clinical expert in the field of intensive care, and 3 epidemiologists. In order to achieve maximum diversity, we selected key informants from both genders, different ages, different levels of management, and the clinical and university environment. Inclusion criteria were having education (minimum a bachelor's degree) and sufficient information to provide health services to cardiovascular patients in disasters, having at least 5 years of experience in disaster-related health fields, having willingness to participate in the study and managers with rich experience, who wanted to participate in the interview. Exclusion criteria were people's unwillingness to continue participating in the study.

The interviews were conducted in an unstructured, face-to-face and in-depth manner. At the choice of the participants, the interviews were conducted at an appropriate time and continued until the data were saturated and a complete description of what was happening about the phenomenon, was obtained " Consent for publication Not Applicable ". At the beginning of the interview, a general question was askedT凶 Prior to the interview, written consent was obtained from the participants, which is appendix 1 ; then, the questions were directed to more specialized ones with regard to the research and in order to gain in-depth information on their experiences. Interviews ranged from 60 to 40 minutes and averaged 50 minutes. Data collection lasted from August to January 2020. The main question was "Did you have a history of presence at the time of accidents and disasters?" To gain a deeper understanding, interviewees were asked questions such as "why?" and "could you explain more, please?" All interviews were digitally recorded and immediately transcribed into texts.

Data analysis Data was analyzed using 'content analysis' was suggested by the Graneheim \& Lundman proposed method (31).

Data were analyzed using content analysis, which uses a systematic and objective method to describe a particular phenomenon. Initially, each recorded interview was immediately typed into a Word file; to comprehend the general meaning of the text and recognize and understand the data, the whole text was read over and over again. Then, the semantic units of the primary codes in the texts were identified and similar codes were merged one or more times and subclasses were formed so that there was the greatest similarity between the codes in each class and the greatest difference between the codes between the classes. After repeated discussions among all the researchers, the classes were integrated and the main classes were formed. MAXQ DA 10 software was used for coding and classification. Given that the findings of qualitative research had to be valid, Goba and Lincoln criteria were used for the accuracy of the study (17). Memoirs were used to validate the findings during the process of researching and writing regular stories and to verify topics by participants. In order to maintain the acceptability of the data, sufficient time and long-term involvement were allocated and also monitoring was done by an 
experienced researcher. The check peer and check expert were used to meet the reliability criterion, and for transferability, a sampling technique with maximum variety, which helped transmit the findings, was considered

\section{Trustworthiness}

Graneheim \& Lundman proposed the credibility, dependability, and transferability of the data to ensure the trustworthiness of results in the content analysis studies (31)Confirmability and credibility of data were enhanced by maximum variation of sampling, and prolonged engagement with data. Furthermore, members of the research team talked over the results to reach an agreement on the codes, categories, and subcategories. Peer checking was carried out by two other researchers who were not members of the research team to enhance the dependability of the results. In addition, to increase the transferability of the results, researchers tried to provide a clear and distinct description of sampling, data collection, data analysis, and reporting of the results.

\section{Results}

In total, 16 participants (8 men and 8 women) were interviewed. Consent was obtained from participants to provide written information $₫$ After analyzing the data Appendix2:Code System Deta Extractions in the Maxqda, 4 main categories were formed based on the risk management cycle, which were Pre-emergency Phase, Emergency Response, and recovery phases (Table-1). At present, the priority of the World Health Organization is cardiovascular diseases with high blood pressure, diabetes and chronic respiratory diseases, which can be considered very important and urgent for global health (16). 
Table 1

Challenges of providing health services for cardiovascular patients in 3 phases of emergencies management cycle

\section{3 phases of emergencies} management cycle

Pre-emergency Phase

\section{Challenges of cardiovascular patients during emergencies} and disasters

1. Lack of training on medication and nutrition [3囚7]

2. Lack of a proper infrastructure [2]

3. Patient Identification Program [1凶6]

4. Lack of manpower [4]

5. 1. Lack of training vulnerable groups [5]

6. Lack of a database of cardiovascular patients(6)

Emergency Response

1. Problems with sleep and rest patterns [8]

2. Lack of health personnel [9]

3. Lack of mental health interventions [12]

4. lack of access to medications [11]

5. Securing the camps [10]

Post-emergency phase
1. Lack of planning and management [13]

2. Patients' psychological problems [14]

4. Fatigue of the workforce [15]

5. Risk management [16] 
Table 2

Characteristics of the experts participating in the study

\begin{tabular}{|c|c|c|c|c|c|}
\hline No. & Age & Gender & $\begin{array}{l}\text { Degree of } \\
\text { education }\end{array}$ & Position, Organizational post & $\begin{array}{l}\text { Work } \\
\text { experience }\end{array}$ \\
\hline 1 & 48 & Man & $\begin{array}{l}\text { PhD in } \\
\text { Nursing }\end{array}$ & $\begin{array}{l}\text { Faculty member of the University of } \\
\text { Medical Sciences }\end{array}$ & 23 \\
\hline 2 & 42 & Man & $\begin{array}{l}\text { Master of } \\
\text { Health }\end{array}$ & Hospital Health Expert & 18 \\
\hline 3 & 40 & Woman & $\begin{array}{l}\text { PhD in } \\
\text { Disaster } \\
\text { Health }\end{array}$ & $\begin{array}{l}\text { Faculty member of the University of } \\
\text { Medical Sciences }\end{array}$ & 21 \\
\hline 4 & 46 & Woman & $\begin{array}{l}\text { PhD in } \\
\text { Disaster } \\
\text { Health }\end{array}$ & $\begin{array}{l}\text { (Manager in the field of health) Faculty } \\
\text { member of the University of Medical } \\
\text { Sciences }\end{array}$ & 25 \\
\hline 5 & 38 & Woman & $\begin{array}{l}\text { Master of } \\
\text { Nursing }\end{array}$ & ICU Nurse & 12 \\
\hline 6 & 32 & Man & Epidemiologist & $\begin{array}{l}\text { Faculty member of the University of } \\
\text { Medical Sciences }\end{array}$ & 15 \\
\hline 7 & 34 & Woman & Epidemiologist & $\begin{array}{l}\text { Faculty member of the University of } \\
\text { Medical Sciences }\end{array}$ & 24 \\
\hline 8 & 47 & Woman & $\begin{array}{l}\text { Master of } \\
\text { Health }\end{array}$ & Hospital Health Expert & 23 \\
\hline 9 & 31 & Woman & $\begin{array}{l}\text { Master of } \\
\text { Health }\end{array}$ & Hospital Health Expert & 13 \\
\hline 10 & 43 & Man & Cardiologist & $\begin{array}{l}\text { Director of the Cardiology Department of } \\
\text { the Hospital }\end{array}$ & 16 \\
\hline 11 & 44 & Woman & $\begin{array}{l}\text { PhD in } \\
\text { Disaster } \\
\text { Health }\end{array}$ & $\begin{array}{l}\text { Faculty member of the University of } \\
\text { Medical Sciences }\end{array}$ & 24 \\
\hline 12 & 40 & Man & $\begin{array}{l}\text { PhD in } \\
\text { Nursing }\end{array}$ & $\begin{array}{l}\text { Faculty member of the University of } \\
\text { Medical Sciences }\end{array}$ & 22 \\
\hline 13 & 38 & Woman & Cardiologist & $\begin{array}{l}\text { Director of the Cardiology Department of } \\
\text { the Hospital }\end{array}$ & 26 \\
\hline 14 & 45 & Man & $\begin{array}{l}\text { Master of } \\
\text { Nursing }\end{array}$ & Hospital Metron & 20 \\
\hline 15 & 36 & Man & $\begin{array}{l}\text { Bachelor of } \\
\text { Nursing }\end{array}$ & ICU Nurse & 15 \\
\hline 16 & 33 & Man & Epidemiologist & $\begin{array}{l}\text { Faculty member of the University of } \\
\text { Medical Sciences }\end{array}$ & 12 \\
\hline
\end{tabular}




\section{1) pre-emergency Phase:}

One of the main challenges in cardiovascular patients is the lack of proper nutrition during emergences' and disasters. Evidence from epidemiological studies suggests that unhealthy lifestyles, smoking, physical inactivity, excessive alcohol consumption, poor diets, and lack of ideal weight account for approximately $80 \%$ of the risk of cardiovascular diseases.

\section{1) lack Of Training On Medication And Nutrition}

Nutrition and dietary patterns play a very important role in the prevention of cardiovascular diseases. There is ample evidence between cardiovascular health, and food intake and eating patterns. According to the results of this study, diets containing fruits and vegetables due to their high fiber, antioxidants and minerals other than sodium along with certain food groups such as legumes, nuts, fish and low-fat and fermented dairy products are suitable for the prevention of cardiovascular diseases (3).

\section{2) Lack of a proper infrastructure}

Another challenge in Pre-emergency Phase times for cardiovascular patients is the lack of proper planning and infrastructures. Hospital managers are always faced with the challenge of how to provide the highest quality level of treatment in health centers with limited resources. In the recent research, capacity planning has been mentioned as one of the most important ways to reduce costs. Most of the patient treatment process in medical centers is such that during treatment, patients need basic measures. This means that in times of disasters, we will face a shortage of equipment. This potentially puts these patients at risk (2).

\section{3) patient Identification Program}

Another challenge is lack of identification of cardiovascular patients. Health documents should be prepared for patients in which demographic characteristics, systolic and diastolic blood pressure, blood lipids, blood sugar and body mass are recorded to have better access to patients' information to provide better services for them in the event of disasters (1).

\section{4) lack Of Manpower}

Lack of manpower is another challenge during disasters. Specialized manpower is the main source of production and provision of services in this sector and it should face a shortage of manpower under no circumstances. Therefore, standardizing the number and how to distribute nursing staff in this ward is necessary to improve the efficiency and quality of services provided to patients and to improve productivity in hospitals. Thus, standardizing the number and how to distribute nursing staff in clinical 
wards, especially the emergency department, is necessary to improve the efficiency and quality of services provided to patients, to make the best use of available facilities and to improve productivity in hospitals (4).

\section{5) lack Of Training Vulnerable Groups}

One of the challenges at this stage is lack of training vulnerable groups All patients have the right to receive appropriate training for maintaining and promoting health and preventing diseases. The more a person knows about his/her illness, the better he/she can deal with it. Training patients can reduce the cost of health care (18)

and increase the quality of care, and ultimately help patients achieve independence and self-sufficiency. In fact, training patients improves and promotes their health. The main purpose of training patients, like other health care processes and as a therapeutic indicator, is to help improve patients' quality of life, promote physical and mental health and strengthen their self-confidence and ultimately improve the level of health in the society. There are many obstacles in the way of patient training during emergences' and disasters (16).

Some factors related to the environment and management of the hospital, such as lack of a suitable location and the short duration of hospitalization, hinder the training of patients; therefore, nursing managers should analyze the situation, identify the barriers to adequate training by nurses and then make appropriate decisions. Studies conducted in the direction of managerial factors are mainly related to elements such as lack of time, manpower as well as scientific and practical competence in the effective implementation of training programs, the need to implement patient training programs in multidisciplinary, and interdisciplinary ways and coordination of health care staff in presenting these programs as well as the need to change the instrumental perspective of health care staff to a humanistic and patient-centered perspective (3).

\section{6) lack Of A Database Of Cardiovascular Patients}

One of the challenges for patients in the Pre-emergency Phase is lack of an information database from patients and their timely identification during disasters. In this regard, cardiovascular patients should be identified. Lifestyle changes in the life of these patients are usually difficult; therefore, it is emphasized that the treatment of vascular risk factors in the form of medication, along with exercise, proper diets and stress control reduces the prevalence of new vascular accidents and mortality. Cardiovascular training programs emphasize behavioral changes and ask patients to follow medication and other medical instructions to participate in their treatment. However, less attention is paid to the fact that this participation requires patients to be confident that they can make lifestyle changes and take medication for the rest of their lives (6). 
The link between nutrition and coronary heart diseases has been established, and a healthier diet reduces mortality after heart attacks. Due to the effect of family on the nutritional status of members, family participation in improving eating habits seems necessary. The family-centered approach has a significant effect on improving the eating patterns of patients with heart attacks that can be very helpful in times of emergences' and disasters (7).

\section{2)emergency Response:}

At the beginning of an emergency, pre-emergency data and rapidly available data from the fi eld are used to estimate the number of people affected, likely impact on health and health services, expected evolution of the situation, and external assistance needed $(19,20)$ The next step is to do rapid health assessments according to a standardised approach. These secondary assessments focus on acute events 36 and do not fully address the needs of patients with CV $(21,22)$

1) problems With Sleep And Rest Patterns

Sleep is one of the important biological periods in a repetitive and regular manner in human beings, which is associated with the restoration of physical and mental strength. One third of a person's life is spent in sleep and deprivation of it will endanger one's health. Changes in sleep patterns, and lack of food, healthy drinking water, proper hygiene and medication are some of the challenges evident in cardiovascular patients at the time of accidents and disasters. Disruptive environmental factors including lack of proper camps, people's commuting, noisy environments, etc., can disrupt patients' sleep patterns (8).

2) Lack Of Health Personnel

Another challenge when responding is lack of experienced manpower to provide health services. According to the WHO, a skilled and experienced workforce in the event of a disaster is someone who has the knowledge, skills and ability to meet the needs of patients. In the event of an unforeseen event, manpower is one of the most important elements in providing care and services. As much as the rational, and experienced combination of this force can have a great impact on the advancement of clinical services, it can provide optimal health services to patients in the event of accidents and disasters (9).

3) Lack Of Mental Health Interventions

Psychological problems are another challenge in patients during disasters. Excitement and extreme stress play an important role in the severity of the disease. Patients will suffer the most at this stage. Problems such as depression, and post- emergences' stress disorders can be very effective on patients in emergencies, which by taking measures and preparing patients in this regard can be reduced to some extent (12).

4) Securing The Camps

Page 11/19 
One of the challenges during emergences'and disasters for CV patients is lack of suitable accommodation centers. The security of the camps and the appropriate space for rest provide conditions for patients to suffer less stress and mental disorders, and as a result, problems such as high blood pressure in these patients are reduced. Living in a camp can lead to poor quality of sleep, both due to lifestyle changes and lack of privacy. Poor quality of sleep in a camp may be directly related to an increase in $\mathrm{BP}$, and as a result, the risk of high blood pressure due to disasters occurs. High salt intake is strongly associated with increased blood pressure. Large-scale natural disasters often lead to poor food availability. In addition, people with high blood pressure have an imbalance between salt intake and salt excretion, which leads to salt retention in the body and increases blood pressure (10).

5) lack of access to medications

Another problem at the time of emergences'and disasters for CV patients is lack of access to medications. After disasters, access to prescribed drugs may be limited or they may be inaccessible. Drug distribution methods must be planned before disasters. Medication information for cardiovascular patients helps take immediate actions to get the medicine. To get a complete list of important medications which may be needed after a disaster, several data sources are important, including data on drug sales to hospitals, clinics and nursing homes, as well as information provided by patients (11).

\section{3)post-emergency Phase :}

The post-emergency phase could also off er opportunities to improve cardiovascular patients care from baseline, including planning for management into the primary $\mathrm{HC}$ system $\otimes$ Patients' psychological problems $₫$ Fatigue of the workforce $\mathbb{R}$ Risk management

\section{1) Lack Of Planning And Management}

One of the challenges at this stage for cardiovascular patients is lack of management and planning. Resource planning and emergency operation management are very important. Alarm systems are very important to inform people about weather conditions, evacuation orders and the closure of roads and medical centers. Family physicians can play an important role in responding to cardiovascular patients in disasters. Principles of care in the event of accidents and disasters must follow a set of standards for the provision of resources, and these standards are established before disasters to follow a specific principle in times of disasters (13).

2) patients' Psychological Problems

Depression, anxiety, and physical isolation are strongly associated with CVD including coronary heart diseases, strokes, and heart failure at the time of emergences' and disasters. Unprecedented psychological stress occurs in cardiovascular patients during emergences'and disasters. A mental health crisis requires both large-scale psychological interventions and disaster management programs in terms 
of mental health. Adequate training of health care personnel and the optimal use of technological advances are of great importance to provide acute interventions of the mental health care (14).

3) fatigue Of The Workforce

A workforce with the knowledge, skills and ability is required to promptly respond for providing services to cardiovascular patients in disasters. This requires that all nurses and health care providers have highquality, evidence-based, and merit-based training programs. We must use all available resources to strengthen the health care workforce. To strengthen and learn health care personnel, evidence-based training opportunities must be provided to make them prepared for disasters (15).

\section{4) Risk Management}

Risk reduction measures are a part of the preparedness strategy of risk management at the time of disasters and emergences'. Having an integrated risk assessment approach and analysis in specific situations is important for cardiovascular patients. Integrated patient assessment in accident-prone areas makes it possible to identify patients and to take appropriate actions in the event of an accident or a disaster. Also, combining the best traditional and modern approaches, fostering community interactions, and relationships, investing in preparedness and improving the use of knowledge in practice, and ensuring adequate human and financial resources are among the useful programs for patients in times of disasters (16).

\section{Discussion}

Disasters are situations in which damages are so severe that it is impossible to control them with available resources. Non-communicable diseases such as cardiovascular diseases, diabetes, chronic respiratory diseases and cancer, with 38 million deaths (68\%), are the leading cause of death worldwide and only about three-quarters ( 28 million) of deaths are due to contagious diseases which also occurs in low- and middle-income countries. During disasters, cardiovascular patients increase and patient management plays a major role in reducing disaster casualties (17). According to the research findings, in times of accidents and disasters, there are challenges for cardiovascular patients, of which management, training, and resources can be cited, based on the priority.

Management of cardiovascular patients is one of the main pillars in times of accidents and disasters. Resource management is important in the event of a sudden increase in the number of patients in centers. Increasing manpower, creating physical spaces and increasing medicine and equipment can also be effective. In most programs of the health system, the treatment needs of these cardiovascular patients and their management are a priority (23).

Disasters often damage the health infrastructure needed to maintain the well-being of people with cardiovascular diseases. This increases the risk of complications, and potentially leads to a long-term prognosis or even death of patients. Due to stress, changes in the pattern and lifestyle of unstable 
patients occur in areas prone to disasters. However, there is now an urgent need to expand public health responses in cardiovascular patients (24). Similarly, in a 2019 study by Benjamin Ryan et al., key managerial impacts after a disaster, including access to medicine, medical services, water, treatment and care, energy and food were assessed. Specific management of patients, including those with cardiovascular diseases, diabetes, mental disorders, and respiratory diseases, will be the major concern after a disaster. Stress and anxiety, loss of sleep, weakness or fatigue, and shortness of breath are common concerns for all non-communicable diseases. Access to medicine and medical services is a priority for all patients after a disaster (25).

The link between nutrition and coronary heart diseases has been established, and a healthier diet reduces mortality after a heart attack. Due to lack of access to adequate food for cardiovascular patients at the time of emergencies and disasters, they may have high blood pressure because of the consumption of canned foods; subsequently, these patients may need antihypertensive drugs. In patients, the mean of blood pressure increases and peaks in the first week and then decreases and returns to the baseline within 6 weeks after a disaster (17). In 2014, Trento et al. stated that patients, including those with cardiovascular diseases, and diabetes, as well as those with kidney problems, are among the most vulnerable and at the high risk because of the type of food they receive. A comprehensive post-emergency plan is essential for both patients and home care providers to ensure that their special needs are met. Home care providers can help patients plan for emergencies at home. On the other hand, it is difficult to intake enough food to provide enough protein during accidents and disasters. The problem is not only food supply, but also the distribution of food between families, the elderly and the sick. The main nutritional disorders are protein malnutrition, iron deficiency, anemia, obesity, and high blood pressure. A nutritional program which includes water supply, waste disposal, cooking utensils and energy, as well as equitable distribution of food during accidents and disasters must be managed. During disasters, patients pay more attention to their eating and health habits, and this may affect their nutritional status in the future (26).

Another challenge which plagues patients during emergencies and disasters, is lack of proper hygiene, which is very important for public health, especially in emergency situations. In 2005 , Noji et al. stated all natural disasters were unique in terms that each affected region in the world had different social, economic and health contexts. There are some similarities between the health effects of various natural disasters, which, if identified, can ensure that health and urgent medical assistance is well managed with limited resources (27).

Training cardiovascular patients is crucial to reduce the severity of the disease. In 2017, Piron et al. stated that intervention focus for patients in need of treatment in acute crises and acute condition management was difficult while in stable conditions, infectious disease management heavily focused on preventive activities which were not possible in critical situations. A patient-centered approach is very important. This includes training patients on self-management, providing an essential medication, and information on self-care. Interventions should be monitored using simple indicators to evaluate their effectiveness. For ongoing health interventions in emergencies, safe access to care and support for health care workers 
are required (16). Also, due to the great importance of psychological training interventions in the prevention of cardiovascular diseases, it is necessary that preventive interventions for cardiovascular diseases include psychological aspects. Also, because of the low cost of training interventions compared to many other ones, more training people of the society will be very useful to prevent cardiovascular diseases (28).

Proper management during emergencies and disasters regarding cardiovascular patients is very important to reduce their stress and anxiety. Supporting vulnerable groups can play an important role. Socio-economic factors are important and influencing on cardiovascular patients at the time of emergencies and disasters. In 2017, Wang Zhang et al. designed and investigated a health management survey. This survey reported lifestyle adjustments, job loss and income reduce, headache exacerbation, dizziness, palpitations and shortness of breath from the questionnaires. They concluded that living outside the home was more likely to exacerbate cardiovascular symptoms among migrants. Job loss was another risk factor related to exacerbated headaches and dizziness (29).

\section{Conclusions}

CVD are the leading cause of death in most countries of the world, including Iran, and there is ample evidence showing the relationship between the severity of cardiovascular diseases and emergencies (30). The findings of this study also showed that at the time of accidents and disasters, cardiovascular patients faced several challenges; according to the risk management cycle, the necessary arrangements had to be done to deal with these challenges. Therefore, the research findings generally showed the high importance of training in the pre- emergency phases. In this regard, training cardiovascular patients on nutrition, medications, and lifestyle changes, as well as psychological support and resource management can be key strategies to reduce morbidity and mortality in the emergency response and post- emergency phases. Thus, training, resource management, and planning in various areas improve the health of the society. Therefore, it is suggested to emphasize the role of training with the aim of increasing awareness, information and psychological support of cardiovascular patients in the event of emergencies and disasters and the existence of planning to provide health services which can be useful.

\section{Limitations}

Due to the implementation of this study among hospital staff, the generalization of results had to be done with caution. Also, because of the time constraints of the participants, the meeting time was short and about 30 minutes virtually and Although this is a qualitative study based on Iranian experts, As is well known, generalizing from qualitative research is based on analytical and inferential not statisticalprobabilistic generalizability.

\section{Abbreviations}

Cardiovascular $=\mathrm{CV} \square$ World Health Organization $=\mathrm{WHO} \square$ Health-Care $=\mathrm{HC} \square$ cardiovascular diseases $=\mathrm{CVD}$ 


\section{Declarations}

Acknowledgments:

Health Economics Research Center of the Management and Information School of Iran University of Medical Sciences, And The authors thank the participants for taking part in this study.

\section{Authors' contributions:}

The authors confirm contribution to the paper as follows: study conception AND design: SHM; data collection: FBS; analysis and interpretation of results: SHM AND FBS; draft manuscript preparation: FBS AND SHM. All authors reviewed the results and approved the final version of the manuscript.

\section{Funding:}

This study was financially supported by the Health Economics Research Center of the Management and Information School of Iran University of Medical Sciences

\section{Availability of data and materials:}

The datasets generated and/or analyzed during the current study are not publicly available due to participant confidentiality but are available from the corresponding author on reasonable request.

\section{Ethics approval and consent to participate:}

This study was approved by the institutional review board of the School of the Health Economics Research Center of the Management and Information Iran University of Medical Sciences(IR.IUMS.REC.1399.513). Participants were informed that participation in the study was voluntary and that they could withdraw from the study at any time. The informed consent included information about the project aims and information about the topic of the interview, voluntary participation in and withdrawal from the research project. The informed consent was obtained from all the participants.

\section{Consent for publication:}

Not applicable

\section{Competing interests:}

None declared.

\section{References}

1. Zayeri F, SADEGHI NR, Noorkojuri H, Bagheri J, Ghazanfari E. Application of classification tree model for determining the effective factors of mortality after coronary bypass surgery in dialysis- 
independent patients. 2012.

2. Brakel P. Bed blocking in hospitals: simulation of the transmural care chain: University of Twente; 2010.

3. Karkhah A, Karkhah M, Ghadimi R. An overview on the role of nutrition and food groups in the prevention of cardiovascular diseases. J Babol Univ Med Sci. 2017;19(3):66-73.

4. Yin P-Y, Chao C-C, Chiang Y-T, editors. Multiobjective optimization for nurse scheduling. International Conference in Swarm Intelligence; 2011: Springer.

5. Khaleghparast S, Mayelafshar M, Hanifi Z, Sari L, Kalaei M, Ghanbari B. Barriers to patient education from the perspective of patients, nurses and doctors in Rajaee cardiovascular medical and research center. Iranian Journal of Cardiovascular Nursing. 2018;7(1):14-23.

6. Isa Maz, Alireza H., Ibrahim Haz. Study of lifestyle of cardiovascular patients.

7. Sadeghzadeh V. Comparison of the Effect of Teaching Cardiopulmonary Resuscitation by means of Traditional and on Knowledge \& Practice of Nursing Students of Zanjan Branch, Islamic Azad University.

8. Nejadshafiee M, Sarhangi F, Rahmani A, Salari MM. Necessity for learning the knowledge and skills required for nurses in disaster. Education strategies in medical sciences. 2016;9(5):328-34.

9. Aoki T, Takahashi J, Fukumoto Y, Yasuda S, Ito K, Miyata S, et al. Effect of the Great East Japan Earthquake on Cardiovascular Diseases-Report From the 10 Hospitals in the Disaster Area-. Circulation Journal. 2013:CJ-12-1594.

10. Lavery AM, Patel A, Boehmer TK, Lee L, Bhavsar T, Thomas J, et al. Notes from the field: pharmacy needs after a natural disaster-Puerto Rico, September-October 2017. Morbidity and Mortality Weekly Report. 2018;67(13):402.

11. Ranjbar F, Akbarzadeh F, Kazemi B, Ranjbar A, Sharifi Namin S, Sadeghi-Bazargani H. Increased Likelihood of Arrhythmic Events Associated with Increased Anxiety in Patients with Implanted Cardiac Defibrillators after the Ahar-Varzegan Earthquake in East Azarbaijan, 2012. Bulletin of emergency and trauma. 2016;4(4):202-10.

12. Chacko S, Randolph R, Morsch G. Disaster Medicine: Public Health Preparedness for Natural Disasters. FP essentials. 2019;487:17-22.

13. Bana T, Hoare J, Letuka P, Ntusi NA. COVID-19 and impact of psychological stress on cardiovascular disease. SA Heart. 2020;17(3):282-6.

14. Iserson KV. Augmenting the disaster healthcare workforce. Western journal of emergency medicine. 2020;21(3):490.

15. Généreux M, Lafontaine M, Eykelbosh A. From science to policy and practice: A critical assessment of knowledge management before, during, and after environmental public health disasters. International journal of environmental research and public health. 2019;16(4):587.

16. Perone SA, Martinez E, Du Mortier S, Rossi R, Pahud M, Urbaniak V, et al. Non-communicable diseases in humanitarian settings: ten essential questions. Conflict and health. 2017;11(1):1-11. 
17. Paladino L, Silverberg M, Charchaflieh JG, Eason JK, Wright BJ, Palamidessi N, et al. Increasing ventilator surge capacity in disasters: ventilation of four adult-human-sized sheep on a single ventilator with a modified circuit. Resuscitation. 2008;77(1):121-6.

18. Yi P, George SK, Paul JA, Lin L. Hospital capacity planning for disaster emergency management. Socio-Economic Planning Sciences. 2010;44(3):151-60.

19. Limbu M, Wanyagi L, Ondiek B, Munsch B, Kiilu K. Kenya inter-agency rapid assessment mechanism (KIRA): A bottom-up humanitarian innovation from Africa. Procedia Engineering. 2015;107:59-72.

20. Organization WH. Managing WHO humanitarian response in the field. Managing WHO humanitarian response in the field: World Health Organization (WHO); 2008.

21. Inter I. perational Guidance for Coordinated Assessments in Humanitarian Crises. 2012.

22. Chan E, Sondorp E. Medical interventions following natural disasters: missing out on chronic medical needs. Asia Pacific Journal of Public Health. 2007;19(1_suppl):45-51.

23. Feizolahzadeh S, Vaezi A, Mirzaei M, Khankeh H, Taheriniya A, Vafaeenasab M, et al. Barriers and facilitators to provide continuity of care to dischargeable patients in disasters: A qualitative study. Injury. 2019;50(4):869-76.

24. Horn RB, Kirsch TD. Disaster Response 2.0: noncommunicable disease essential needs still unmet. American Public Health Association; 2018.

25. Ryan BJ, Franklin RC, Burkle FM, Smith EC, Aitken P, Leggat PA. Determining key influences on patient ability to successfully manage noncommunicable disease after natural disaster. Prehospital and disaster medicine. 2019;34(3):241-50.

26. Trento L, Allen S. Hurricane Sandy: nutrition support during disasters. Nutrition in Clinical Practice. 2014;29(5):576-84.

27. Noji EK. Public health issues in disasters. Critical care medicine. 2005;33(1):S29-S33.

28. Besharat, Hosseini, Asma S, Ehsan B, Jahed, Hossein Ali, et al. Educational intervention model based on general lifestyle and heart health. Journal of Research in Educational Systems. 2015; 9 (29): 7-29.

29. Zhang W, Ohira T, Yasumura S, Maeda M, Otsuru A, Harigane M, et al. Effects of socioeconomic factors on cardiovascular-related symptoms among residents in Fukushima after the Great East Japan Earthquake: a cross-sectional study using data from the Fukushima Health Management Survey. BMJ open. 2017;7(6):e014077.

30. Abedi H, Bik Mohammadi S, Abdeyazdan G, Nazari H. A survey on the the lifestyle of the heart desease patients after discharge from hospital in urmia seyyed alshohada in 1391. Nursing And Midwifery Journal. 2014;11(12):0-.

31. Graneheim UH, Lundman B. Qualitative content analysis in nursing research: concepts, procedures and measures to achieve trustworthiness. Nurse Educ Today. 2004;24(2):105-12. https://doi.org/10.1016/j.nedt.2003.10.001.

\section{Supplementary Files}


This is a list of supplementary files associated with this preprint. Click to download.

- Appendix.docx 